\title{
Lamellodiscus (Monogenea: Diplectanidae) parasites of Dentex macrophthalmus (Teleostei: Sparidae) from the North Atlantic coast of Africa, with a redescription of $L$. dentexi Aljoshkina, 1984, and description of three new species
}

\author{
Arfang Diamanka ${ }^{1,2}$, Lassâd Neifar ${ }^{3}$, Antoine Pariselle ${ }^{2}$ and Louis Euzet ${ }^{4}$ \\ ${ }^{1}$ Laboratory of Parasitology and Laboratory of Aquatic Animals Pathologies, Khaled Bin Sultan Living Oceans Foundation, \\ Department of Animal Biology, Faculty of Sciences and Technologies, University Cheikh Anta Diop, Dakar, Senegal; \\ ${ }^{2}$ UR 203, UMR 5554, IRD/ISE-M, Laboratoire d'Écologie et de Systématique, Campus de Bel Air, BP 1386, Dakar, Senegal; \\ ${ }^{3}$ Laboratoire de Biodiversité et Écosystèmes Aquatiques, Faculté des Sciences de Sfax, BP 1171, 3000 Sfax, Tunisie; \\ ${ }^{4}$ Station Méditerranéenne de l'Environnement Littoral, Université de Montpellier II, 2 rue des Chantiers, 34200 Sète, France
}

\begin{abstract}
Lamellodiscus dentexi Aljoshkina, 1984, a gill parasite of Dentex macrophthalmus (Bloch), is redescribed based on new material from the northwest coast of Africa (Senegal and Morocco). Three new species of Lamellodiscus Johnston et Tiegs, 1922 from D. macrophthalmus are described, Lamellodiscus toguebayei sp. n., L. vicinus sp. n., and L. triacies sp. n., all belonging to the "ignoratus" group. They can be distinguished from all other species of this group by the size and shape of male copulatory organ and sclerotised parts of the haptor. Considering the peculiar morphology of the male copulatory organ (long and thin tube) we propose to put together L. dentexi, L. virgula Euzet et Oliver, 1967 and L. obeliae Oliver, 1973 to form the "elongatus" type within the "elegans" group.
\end{abstract}

Keywords: Monogenea, Diplectanidae, Lamellodiscus dentexi, Lamellodiscus toguebayei, Lamellodiscus vicinus, Lamellodiscus triacies, Dentex macrophthalmus, Senegal, Morocco

Lamellodiscus Johnston et Tiegs, 1922 (Monogenea: Diplectanidae) is currently composed of 52 described species (Euzet and Oliver 1967, Kritsky et al. 2000, Amine and Euzet 2005, Amine et al. 2006, 2007, Neifar 2008, Boudaya et al. 2009, Justine and Briand 2010) that have been mainly studied in sparids. Sparid fishes consist of approximately 115 species in 33 genera that are broadly distributed in tropical and temperate coastal waters (Nelson 2006). Diplectanids often show strict host-specificity (Oliver 1992); thus, it is a safe prediction that many other species of Lamellodiscus are still undescribed (Poulin and Mouillot 2005, Justine 2007).

Along the Atlantic coast of Africa, 29 species of Sparidae are reported (Quéro et al. 1990) on which only seven Lamellodiscus species have been described: L. dentexi Aljoshkina, 1984 from the large-eye dentex Dentex macrophthalmus (Bloch) by Aljoshkina (1984); L. elegans Bychowsky, 1957, L. ergensi Euzet et Oliver, 1966 and L. ignoratus Palombi, 1949 reported from the white seabream Diplodus sargus cadenati de la Paz, Bauchot et Daget by Justine (1985); and L. sarculus and L. sigillatus from Pagrus caeruleostictus (Valenciennes) and L. rastel- lus from Pagrus auriga (Valenciennes) described by Neifar et al. (2004).

Collections of $D$. macrophthalmus from the coast of Senegal near Dakar during February 2009, and from off Rabat, Morocco during April 2009, revealed, in addition to L. dentexi, three species of Lamellodiscus that are new to science. The purpose of this paper is to provide a redescription of $L$. dentexi and descriptions of three new species.

\section{MATERIALS AND METHODS}

Specimen collection and preparation. Specimens of Dentex macrophthalmus, 152 from Dakar, Senegal and 5 from off Rabat, Morocco, were identified using Blache et al. (1970) and Bellemans et al. (1988). Fish were dissected immediately or frozen until examination. Gill arches were removed and placed in separate Petri dishes containing seawater and examined for parasites under incident light, using stereomicroscope. Diplectanids were detached from the gills with a strong water current and transferred to a dish containing filtered seawater. Some parasites were partially compressed beneath slide and coverslip and examined using an optical microscope. Other parasites were 

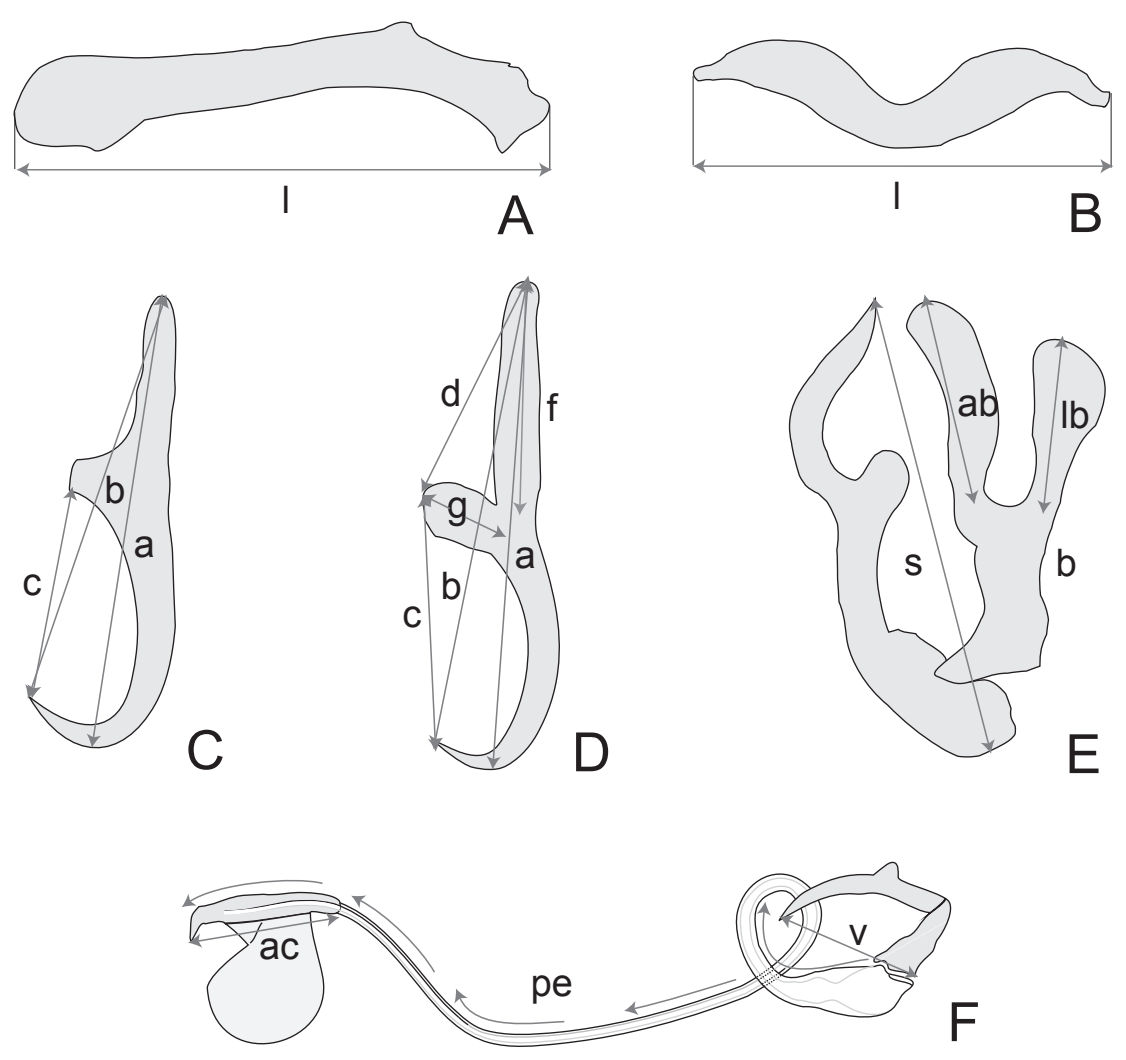

Fig. 1. Morphology of Lamellodiscus Johnston et Tiegs, 1922. Measurements of various sclerotised organs. A - dorsal bar: 1 - total length; B - ventral bar: 1 - total length; C - dorsal anchor: a - total length, b - shaft-point length, c - distance guard-point; $\mathbf{D}$ - ventral anchor: a - total length, $\mathrm{b}$ - distance shaft-point, $\mathrm{c}$ - distance guard-point, $\mathrm{d}$ - distance shaft-guard, $\mathrm{f}$ - shaft length, $\mathrm{g}$ - guard length; E - male copulatory complex ("lyre" type): s - simple piece length, b - bifurcated piece, ab - axial branch length, lb - lateral branch length; F - male copulatory complex ("elongatus" type): v - vectis, pe - penis length, ac - accessory piece.

transferred and mounted onto a slide in a drop of ammonium picrate-glycerol (Malmberg 1957). The preparation was then covered with a round coverslip and sealed with Glyceel (made after Bates 1997).

Morphological analysis. Drawings were made using a Leitz microscope equipped with a drawing tube, then scanned and redrawn with CorelDraw software. For male copulatory organ (MCO) of $L$. dentexi we use the terms "vectis" (see Boudaya et al. 2009) for the sclerotised piece articulated with the proximal part of the penis and "accessory pieces" for the sclerotised piece placed at the distal part of the penis. As proposed by Neifar et al. (2004) for the nomenclature of sclerotised piece, the "lyre"shaped MCO is composed of a bifurcated and a simple piece. For the bifurcated piece of MCO we use the terms axial and lateral for internal and external branch, respectively. Terms and measures of the sclerotised structures are presented in Fig. 1. Measurements, made on specimens fixed in Malmberg's fluid, taken using a DM2500 Leica microscope, a DFC320 Leica digital camera and Leica Application Software v 3.0, are given in micrometres followed in parentheses by the range and the number of observations (n). Voucher specimens of $L$. dentexi and the holotype and paratypes of the new species are deposited in the collections of the Muséum National d'Histoire Naturelle, Paris (MNHN), with some paratypes also in the Parasitic Worm
Collection at the Natural History Museum, London (BMNH) and the collection of the Institute of Parasitology, Biology Centre of the Academy of Sciences of the Czech Republic, České Budějovice (IPCAS).

We were not able to examine the holotype of $L$. dentexi (675-N 495/7: Atlantic Research Institute of Marine Fisheries and Oceanography, Kaliningrad) which was lost (Dr. G. Rodjuk, pers. comm.).

\section{RESULTS}

Lamellodiscus dentexi Aljoshkina, 1984

Fig. 2

Morphological redescription. Diplectanidae, Lamellodiscinae. Adults 1760 (1581-1981, $\mathrm{n}=10)$ long including haptor, maximum width $400(387-420, \mathrm{n}=10)$ at level of ovary. Haptor $257(176-333, \mathrm{n}=10)$ wide. Dorsal and ventral lamellodiscs of "elegans" group (Oliver 1987), subequal, $42(38-46, \mathrm{n}=20)$ in diameter, with 10 concentric lamellae; anterior lamella forming complete ring 18 $(16-21, \mathrm{n}=6)$ maximum wide. Dorsal anchor with incipient guard, a: $59(56-60, \mathrm{n}=20)$; b: $55(53-58, \mathrm{n}=20)$; c: $29(27-31, n=20)$. Two lateral dorsal bars with rounded and curved distal end $57(54-60, n=20)$ long. Ventral 

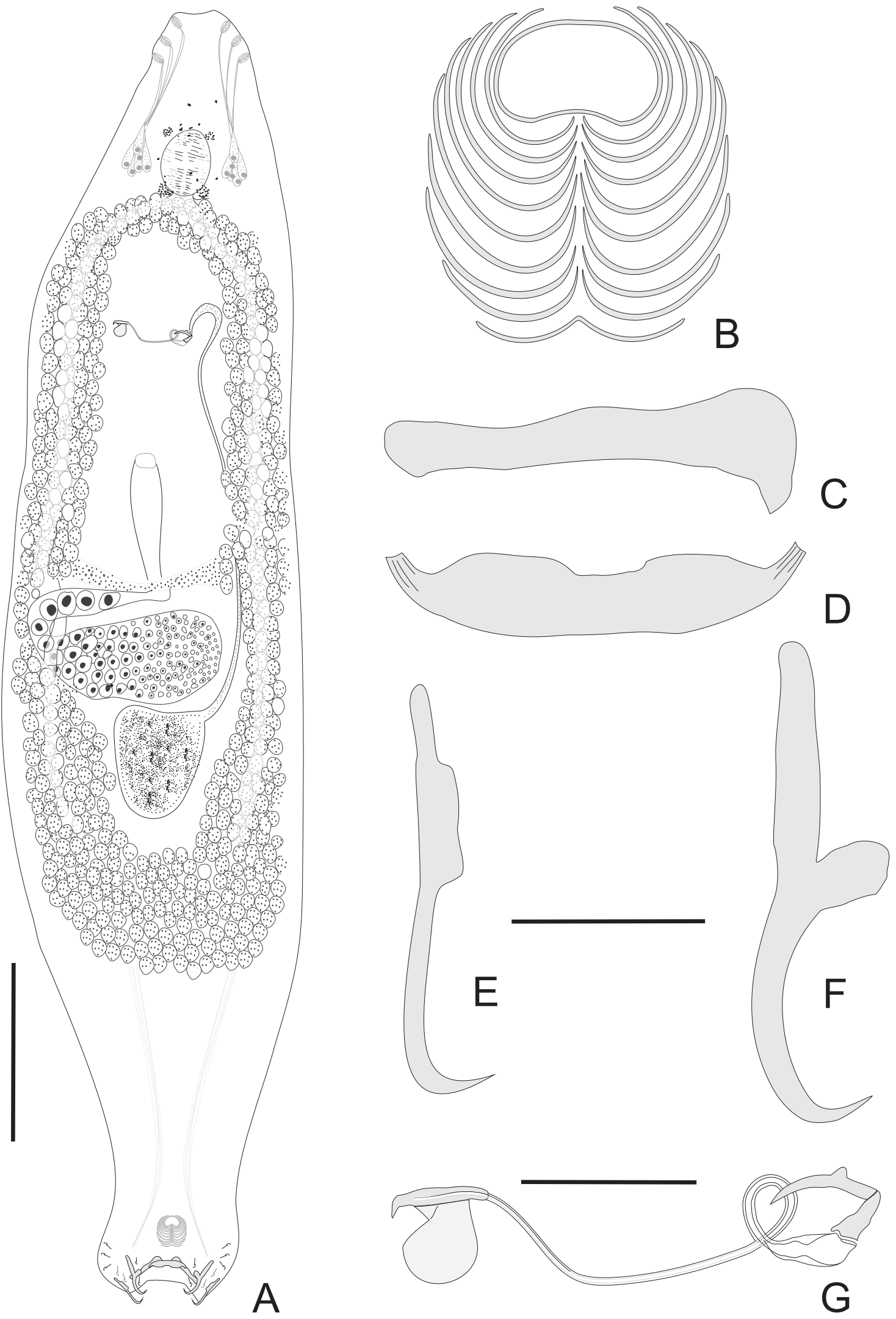

Fig. 2. Lamellodiscus dentexi Aljoshkina, 1984 from Dentex macrophthalmus off Dakar, Senegal. A - entire worm, ventral view, composite drawing of three live and five fixed specimens; B - lamellodisc ("elegans" type); C - dorsal bar; D - ventral bar; E - dorsal anchor; F - ventral anchor; $\mathbf{G}$ - male copulatory organ. Scale bars: A $=250 \mu \mathrm{m} ; \mathrm{B}-\mathrm{F}=25 \mu \mathrm{m} ; \mathrm{G}=50 \mu \mathrm{m}$. 
anchor with developed handle, wide guard, long shaft and small point; a: 67 (64-69, $\mathrm{n}=19)$; b: $64(61-66, \mathrm{n}=19)$; c: $32(29-36, \mathrm{n}=19)$; d: 34 (31-37, n=19); f: 33 (31$35, \mathrm{n}=19)$; g: $12(11-14, \mathrm{n}=19)$. Ventral median bar $60(58-63, \mathrm{n}=10)$ long, with median constricted portion and anteriorly curved ends. Fourteen similar uncinuli (seven pairs) $11.7(10-14, \mathrm{n}=25)$ long, with disposition as shown in Fig. 2A. Cephalic glands lateral to pharynx, with numerous ducts leading to three head organs on each sides of anterior margin. Four cluster of ocellar pigment granules, posterior pair more developed. Mouth anterior, subterminal ventral. Muscular pharynx spherical, 95 $(77-124, \mathrm{n}=10)$ in diameter. Oesophagus short. Lateral oesophageal glands present. Two simple lateral intestinal caeca terminating blindly between testis and haptor. Genital aperture median ventral. Subspherical testis intercaecal in posterior quarter of body. Vas deferens originating on anterosinistral side of testis, runs anteriorly enlarging to form curved fusiform seminal vesicle anterior to MCO. Prostatic reservoir and prostatic duct not seen. MCO with basal vectis, sclerotised, V-shaped, v: $21(19-25, \mathrm{n}=10)$ long, articulated with bulbous base of sclerotised penis. Penis elongated, pe: $143(141-147, \mathrm{n}=10)$ long, flagelliform, hollow, forming one loop near base, distal part with sclerotised accessory piece, ac: $21(17-25, \mathrm{n}=10)$ long, ending in a hook and with a thin rounded ventral plate. Ovary median, subequatorial, anterior to testis, looping dorso-ventrally around right intestinal caecum. Vagina not observed. Lateral vitelline follicles well developed, coextensive with intestinal caeca, contiguous anterior to MCO and posterior to testis. Transverse vitelloduct united medially anterior to ovary. Eggs not observed.

Type host: Dentex macrophthalmus (Bloch, 1791) (Sparidae, Perciformes).

Type locality: Northwest coast of Africa (after Aljoshkina 1984).

Other 1 ocalities: Dakar $\left(14^{\circ} 40^{\prime} 41^{\prime \prime} \mathrm{N}, 17^{\circ} 27^{\prime} 34^{\prime \prime} \mathrm{W}\right)$,

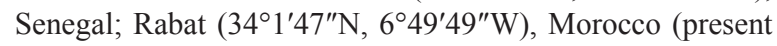
paper).

Site of infection: Gills, the extremity of the filament.

Type material: Neotype (mounted in ammonium picrateglycerol): MNHN No. HEL 155 Tf 180; 5 vouchers specimens (mounted in ammonium picrate-glycerol): MNHN Nos. HEL 155 Tf 180, HEL 156 Tf 181, HEL 157 Tf 182, HEL 158 Tf 183.

Prevalence : $12 \%, 19$ infected of 157 fish examined.

Remarks. Here we give a redescription of $L$. dentexi because the original illustrations include some inaccuracies (e.g. distal accessory piece is drawn superposed with proximal rounded base of the penis and with the vectis, leading to confusion between these sclerotised pieces).

On the gills of D. macrophthalmus, L. dentexi is always attached at the extremity of the filament and can be easily distinguished from its congeners by having the largest body size.
Based on the structure of lamellodisc, three morphological groups are recognised by Justine and Briand (2010): "ignoratus", "elegans", and "tubulicornis". Lamellodiscus dentexi belongs to the "elegans" group. Similarly, Oliver (1987) distinguished among Lamellodiscus three different types based on the morphology of the MCO: "lyre", "forked", and "polymorphous". Because of the morphology of its MCO with a long and thin penis articulated with a vectis (see Boudaya et al. 2009) and a true accessory piece (i.e. placed at the distal extremity of the penis), $L$. dentexi should be placed in the latter type. Two other species, L. virgula Euzet et Oliver, 1967 from Pagellus acarne (Risso) and L. obeliae Oliver, 1973 from P. bogaraveo (Brünnich), present the same MCO morphology, but have been placed by Oliver (1987) in the "forked" group. Considering the similarity and the special feature of these MCOs, we propose a new type of MCO morphology, herein named "elongatus".

In conclusion, L. dentexi, as L. virgula and L. obeliae, belongs to the "elegans" group (based on lamellodisc) and "elongatus" type (based on MCO). Lamellodiscus dentexi can be distinguished from these two other species by the size of the accessory piece of the MCO (21 vs. 60 for L. virgula) and by the shape of its accessory piece (presence of a rounded ventral plate vs. absence in L. obeliae).

\section{Lamellodiscus toguebayei sp. n.}

Fig. 3

Morphological description. Diplectanidae, Lamellodiscinae. Adults $589(504-694, \mathrm{n}=26)$ long including haptor; maximum width $146(121-179, \mathrm{n}=26)$ at level of ovary. Haptor $153(135-165, \mathrm{n}=26)$ wide, bilaterally lobed. Dorsal and ventral lamellodiscs of "ignoratus" group with 10 concentric rows of lamellae 41 (37-47, $\mathrm{n}=52$ ) in diameter; anterior row forming circular complete ring $19(15-22, \mathrm{n}=52)$ in diameter. Dorsal anchor with incipient guard, a: $48(43-52, \mathrm{n}=52)$ b: $45(40-49$, $\mathrm{n}=52)$; c: $25(20-29, \mathrm{n}=52)$. Two lateral dorsal bars with spatulate medial end and curved lateral end, 66 (60$72, \mathrm{n}=52$ ) long. Ventral anchor with protuberant handle, narrow guard, bent shaft and short point; a: 59 (53-64, $\mathrm{n}=52)$; b: $56(50-61, \mathrm{n}=52)$; c: $34(27-38, \mathrm{n}=52)$; d: $23(16-27, \mathrm{n}=52)$; f: $30(24-34, \mathrm{n}=50)$; g: 13 (9$16, \mathrm{n}=50)$. Ventral median bar "V-shaped" 57 (52-63, $\mathrm{n}=26$ ) long with constricted median part and curved ends. Fourteen similar uncinuli (seven pairs) 11 (10-13, $\mathrm{n}=25$ ) long, with diplectanid disposition (Fig. 3 A). Cephalic glands lateral to pharynx, with numerous ducts leading to three head organs on each sides of anterior margin. Ocellar pigment granules scarce, scattered in prepharyngeal part of body. Mouth anterior, subterminal, opening ventrally. Pharynx spherical, $47(39-54 ; n=15)$ in diameter. Oesophagus short. Lateral oesophageal glands present. Simple lateral intestinal caeca not united posteriorly. Subspherical testis intercaecal in posterior half of body. Vas deferens emerging from anterosinistral side of 

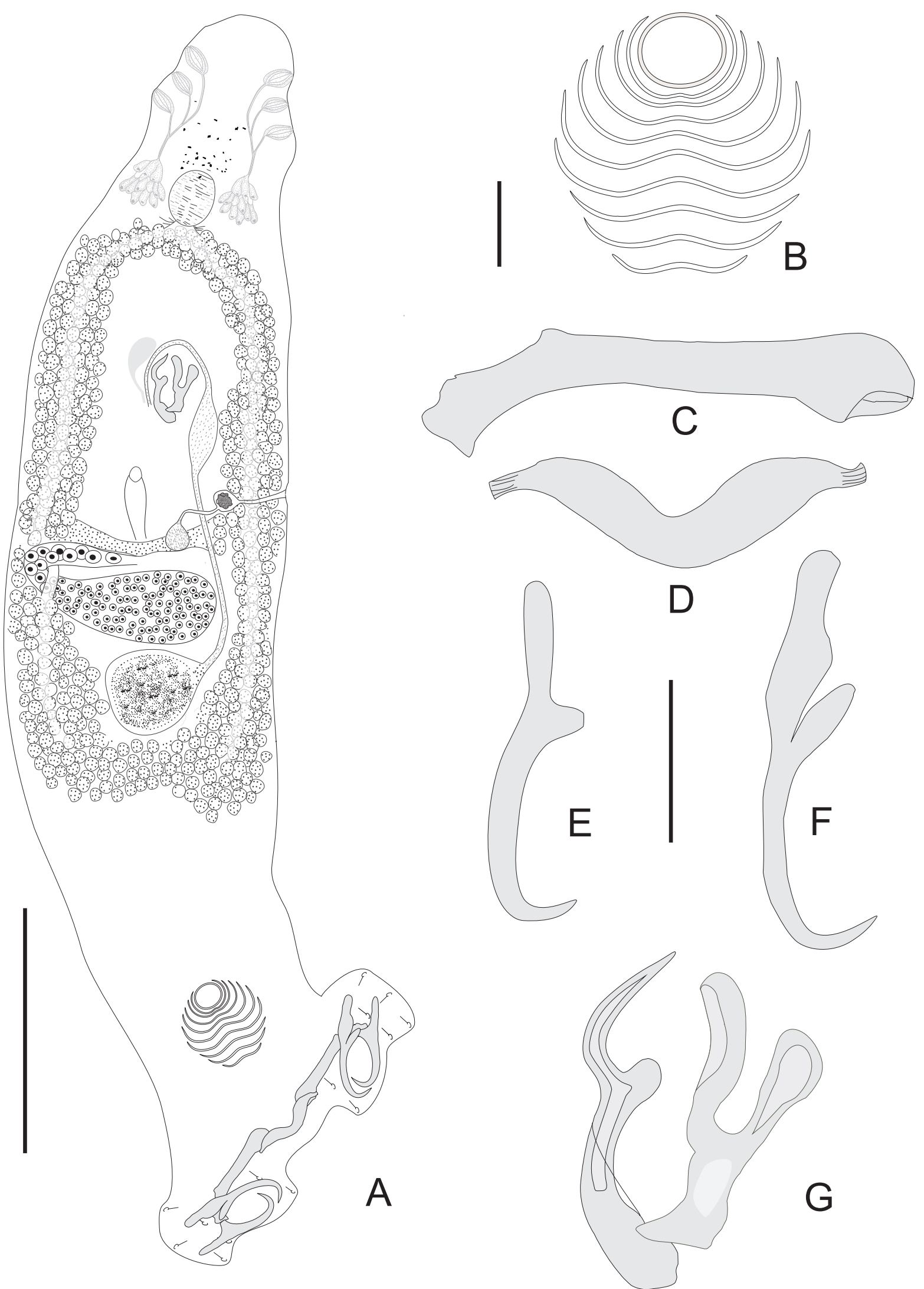

Fig. 3. Lamellodiscus toguebayei sp. n. from Dentex macrophthalmus off Dakar, Senegal. A - entire worm, ventral view, composite drawing of five live specimens; B - lamellodisc ("ignoratus" group); C - dorsal bar; D - ventral bar; E - dorsal anchor; F - ventral anchor; $\mathbf{G}$ - male copulatory organ. Scale bars: $A=100 \mu \mathrm{m} ; \mathrm{B}-\mathrm{G}=25 \mu \mathrm{m}$. 
testis, not encircling left intestinal caecum, enlarging to form seminal vesicle. Vas deferens passing on right side, anterior to $\mathrm{MCO}$. Prostatic reservoir pyriform, anterior to MCO. MCO of "lyre" morphology, with two sclerotised, articulated pieces. Simple piece with sickle-shaped distal third, s: 54 (49-59, $\mathrm{n}=24)$ long. Bifurcated piece with lateral rounded-end branch $\mathrm{lb}: 21(19-23, \mathrm{n}=26)$ shorter than axial branch ab: $28(24-30, n=26)$. Distal extremity of axial branch spoon-shaped. Ovary median, subequatorial, anterior to testis, looping dorsoventrally around right intestinal caecum. Mehlis' glands not observed. Vaginal aperture sinistral, between MCO and ovary, with funnelshaped opening, enlarged vaginal chamber often filled with sclerotised globular mass. Vaginal chamber connected with narrow duct to globular seminal receptacle, anterior to ovary. Vitelline follicles lateral, coextensive with intestinal caeca, contiguous anterior to $\mathrm{MCO}$ and posterior to testis. Eggs not seen.

Type host: Dentex macrophthalmus (Bloch, 1791) (Sparidae, Perciformes).

Type 1 o c a lity: Dakar $\left(14^{\circ} 46^{\prime} 24^{\prime \prime} \mathrm{N}, 17^{\circ} 25^{\prime} 29^{\prime \prime} \mathrm{W}\right)$, Senegal. Other locality: Rabat $\left(34^{\circ} 1^{\prime} 47^{\prime \prime} \mathrm{N}, 6^{\circ} 49^{\prime} 49^{\prime \prime} \mathrm{W}\right)$, Morocco. Site of infection: Gills between secondary gill lamellae. Type materia 1: Holotype (mounted in ammonium picrateglycerol): MNHN No. HEL 159 Tf 184; 14 paratypes (mounted in ammonium picrate-glycerol): MNHN Nos. HEL $159 \mathrm{Tf}$ 184, HEL 160 Tf 185, HEL 161 Tf 186; 9 paratypes (mounted in ammonium picrate-glycerol): BMNH 2010.8.11.1-3, 2010.8.11.4-9; and 7 paratypes (mounted in ammonium picrate-glycerol): IPCAS No. M-509.

Prevalence : 94\%, 147 infected of 157 fish examined.

Etymology: The name toguebayei is given in honour of Professor Bhen Sikina Toguebaye from the University Cheikh Anta Diop, Dakar, Senegal.

Remarks. From the morphology of the squamodisc and male copulatory organ, this new species belongs to the "ignoratus" group (Oliver 1987). The presence of simple dorsal lateral bars enlarged at the axial end places this species in the "ignoratus" s. st. subgroup (Amine and Euzet 2005). This subgroup includes 13 species, L. pagrosomi Murray, 1931; L. ignoratus Palombi, 1949; L. fraternus Bychowsky, 1957; L. erythrini Euzet et Oliver, 1967; L. knoepffleri Oliver, 1969; L. acanthopagri Roubal, 1981; L. sarculus Neifar, Euzet et Oliver, 2004; L. sigillatus Neifar, Euzet et Oliver, 2004; L. rastelus Neifar, Euzet et Oliver, 2004; L. falcus Amine, Euzet et KechemirIssad, 2006; L. neifari Amine, Euzet et Kechemir-Issad, 2006; L. confusus Amine, Euzet et Kechemir-Issad, 2007; and L. crampus Neifar, 2008. Lamellodiscus toguebayei can be easily distinguished from all of these species, except L. sarculus, by the sickle-shape of distal third of the simple piece of MCO. Lamellodiscus toguebayei differs from $L$. sarculus by the length of the lateral branch of the bifurcated piece of the MCO (21 vs. 12, respectively).
Lamellodiscus vicinus $\mathrm{sp}$. $\mathrm{n}$.

Fig. 4

Morphological description. Diplectanidae, Lamellodiscinae. Adults $630(523-902, \mathrm{n}=25)$ long including haptor; maximum width $143(111-168, \mathrm{n}=25)$ at level of ovary. Haptor $160(115-222, \mathrm{n}=25)$ wide, bilaterally lobed. Dorsal and ventral lamellodiscs of "ignoratus" group, $46(40-50, \mathrm{n}=50)$ in diameter, with 10 concentric rows of lamellae; anterior row forming circular complete ring $25(21-28, \mathrm{n}=50)$ in diameter. Dorsal anchor with incipient guard, a: $36(33-39, \mathrm{n}=50)$; b: $34(30-37, \mathrm{n}=50)$; c: $20(18-22, \mathrm{n}=50)$. Two lateral dorsal bars with spatulate medial end and bent third lateral end, 62 (56-69, $\mathrm{n}=50$ ) long. Ventral anchor with developed handle, wide guard, bent shaft and short point; a: $41(37-45, \mathrm{n}=50)$; b: $39(35-43, \mathrm{n}=50) ; \mathrm{c}: 24(21-27, \mathrm{n}=50)$; $\mathrm{d}: 16(14-18$, $\mathrm{n}=48)$; f: $19(17-22, \mathrm{n}=50)$; g: $8.5(6-10, \mathrm{n}=50)$. Ventral median bar $78(66-88, \mathrm{n}=50)$ long, with constricted median part and tapered ends. Fourteen similar uncinuli (seven pairs) $11(9-13, \mathrm{n}=25)$ long, with diplectanid disposition. Cephalic glands lateral to pharynx, with numerous ducts leading to three head organs on each sides of anterior margin. Ocellar pigment granules numerous, scattered in prepharyngeal part of body. Mouth anterior, subterminal, opening ventrally. Pharynx spherical, 45 $(40-49, \mathrm{n}=10)$ in diameter. Oesophagus short. Lateral oesophageal glands present. Simple lateral intestinal caeca not united posteriorly. Subspherical testis intercaecal in posterior half of body. Vas deferens emerging from anterosinistral side of testis, not encircling left intestinal caecum, enlarging to form seminal vesicle. Vas deferens passing on right side, anterior to $\mathrm{MCO}$. Prostatic reservoir pyriform, anterior to MCO. MCO of "lyre" morphology (sensu Oliver 1987), with two sclerotised, articulated pieces. Simple piece of MCO straight and slightly folded at distal quarter s: $50(47-57, \mathrm{n}=25)$ long, base covered by a thin sclerotised skirt-like envelope. Bifurcated piece of MCO with lateral spatulate branch lb: 18 (16-21, $\mathrm{n}=23)$ shorter than axial branch ab: $28(25-31, \mathrm{n}=25)$. Distal extremity of axial branch of simple piece spoonshaped with striped cavity. Ovary median, subequatorial, anterior to testis, looping dorso-ventrally around right intestinal caecum. Mehlis' glands and ootype not observed. Vaginal aperture sinistral with funnel-shaped opening. Vaginal chamber often filled with slightly sclerotised globular mass. Vaginal chamber connected with narrow duct to globular seminal receptacle located anterior to ovary. Vitelline follicles lateral, coextensive with intestinal caeca, contiguous anterior to prostatic reservoir and posterior to testis. Eggs not observed.

\footnotetext{
Type host: Dentex macrophthalmus (Bloch, 1791) (Sparidae, Perciformes).

Type locality: Dakar $\left(14^{\circ} 40^{\prime} 41^{\prime \prime} \mathrm{N}, 17^{\circ} 27^{\prime} 34^{\prime \prime} \mathrm{W}\right)$, Senegal. Other 1 ocality: Rabat $\left(34^{\circ} 1^{\prime} 47^{\prime \prime} \mathrm{N}, 6^{\circ} 49^{\prime} 49^{\prime \prime} \mathrm{W}\right)$, Morocco. $\mathrm{S}$ ite of infection: Gills between secondary gill lamellae.
} 

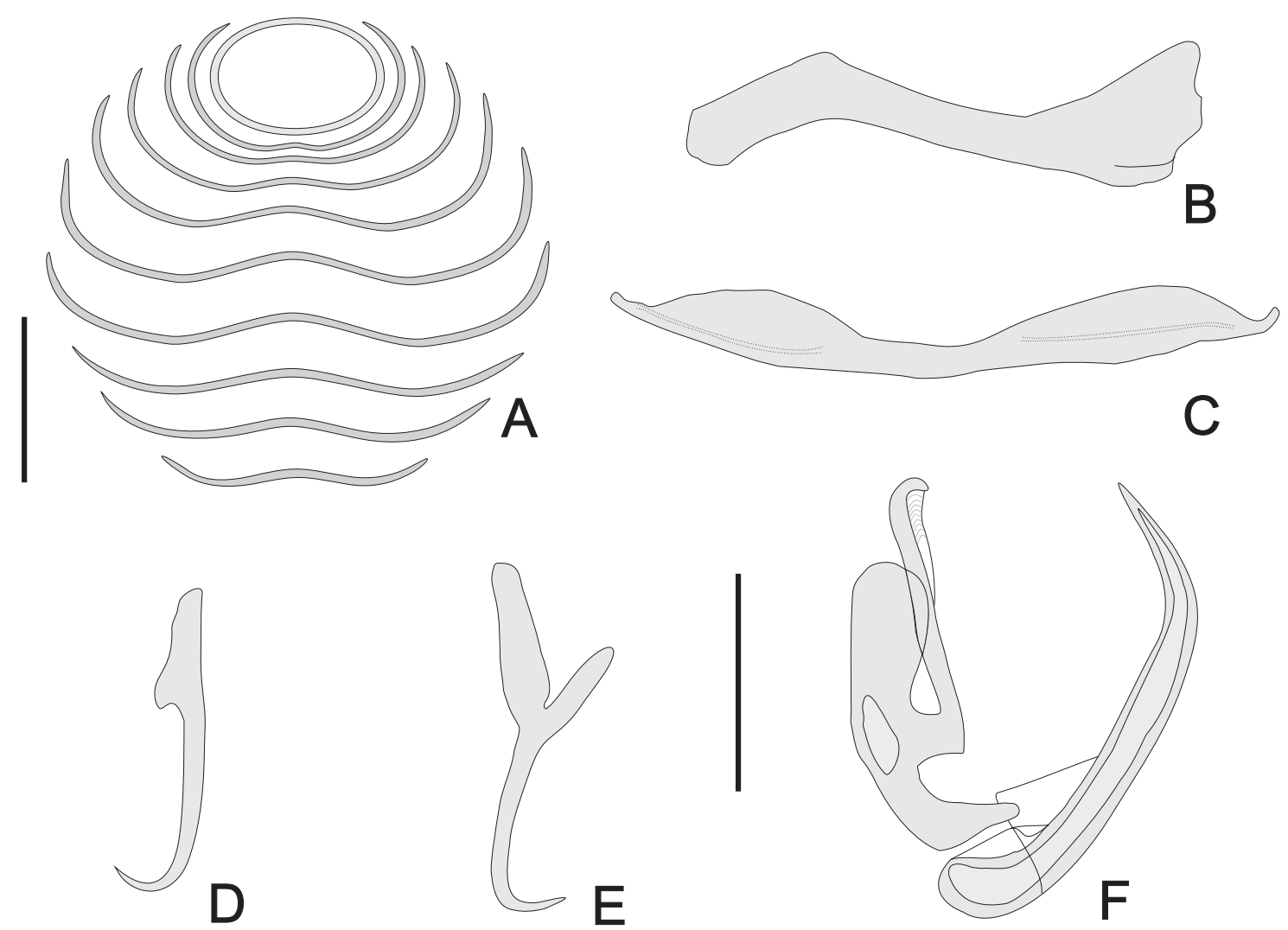

Fig. 4. Lamellodiscus vicinus sp. n. from Dentex macrophthalmus off Dakar, Senegal. A - lamellodisc ("ignoratus" group); B - dorsal bar; C - ventral bar; D - dorsal anchor; $\mathbf{E}$ - ventral anchor; $\mathbf{F}$ - male copulatory organ. Scale bars $=25 \mu \mathrm{m}$.

Type materia 1: Holotype (mounted in ammonium picrateglycerol): MNHN No. HEL 162 Tf $187 ; 5$ paratypes (mounted in ammonium picrate-glycerol): MNHN Nos. HEL $162 \mathrm{Tf}$ 187, HEL 163 Tf 188, HEL 164 Tf 189; 1 paratypes (mounted in ammonium picrateglycerol): BMNH 2010.8.11.10; and 2 paratypes (mounted in ammonium picrate-glycerol): IPCAS No. M-511.

Prevale n c e : $27 \%, 42$ infected of 157 fish examined.

Etymology: From the Latin "vicinus" (= neighbour). The name reflects that $L$. vicinus is morphologically close to L. crampus Neifar, 2008.

Remarks. From the morphology of the squamodisc, dorsal lateral bars and $\mathrm{MCO}$, this species belongs to the "ignoratus" group (Oliver 1987) and "ignoratus" s. st. subgroup (Amine and Euzet 2005). Lamellodiscus vici$n u s$ can be easily distinguished from all species of this subgroup, except L. fraternus and L. crampus, by the spoon-shape morphology of the axial branch of bifurcated piece. Lamellodiscus vicinus can be distinguished from L. fraternus by the size of the MCO (25 vs. 50, respectively) and the shape of the anchors. Morphology of the axial branch of bifurcated piece is the main characteristic on which $L$. vicinus and L. crampus are differentiated: the former has its extremity as a striped cavity whereas the latter has 5-6 spines.

\section{Lamellodiscus triacies sp. n.}

Fig. 5

Morphological description. Diplectanidae, Lamellodiscinae. Adults $630(564-900, \mathrm{n}=27)$ long including haptor; maximum width $135(92-161, \mathrm{n}=27)$ at level of ovary. Haptor $148(118-183, \mathrm{n}=27)$ wide, bilaterally lobed. Dorsal and ventral lamellodiscs of "ignoratus" group, $45(39-55, \mathrm{n}=54)$ in diameter, with 10 concentric rows of lamellae; anterior forming subcircular complete ring $23(20-26, \mathrm{n}=54)$ in diameter. Dorsal anchor with incipient guard, a: $40(35-43, \mathrm{n}=54)$; b: $38(35-42$, $\mathrm{n}=54)$; $: 19(17-23, \mathrm{n}=52)$. Two lateral dorsal bars with spatulate medial end and curved lateral end, 61 (57-65, $\mathrm{n}=53$ ) long. Ventral anchor with developed handle, wide guard, bent shaft and short point; a: $49(46-53, \mathrm{n}=54)$; $\mathrm{b}$ : $47(45-50, \mathrm{n}=54)$; c: $25(22-29, \mathrm{n}=54)$; $: 22(18-26$, $\mathrm{n}=54)$; f: $27(23-29, \mathrm{n}=54)$; g: $9(8-12, \mathrm{n}=53)$. Ventral median bar $64(61-68, \mathrm{n}=27)$ long with constricted median part and curved ends. Fourteen similar uncinuli (seven pairs) $11(10-12, \mathrm{n}=25)$ long, with diplectanid disposition. Cephalic glands lateral to pharynx, with numerous ducts leading to three head organs on each sides of anterior margin. Ocellar pigment granules scattered in anterior part of body. Mouth anterior, subterminal, opening ventrally. Pharynx spherical, $52(49-58, \mathrm{n}=11)$ in diameter. Oesophagus very short. Lateral oesophageal glands 

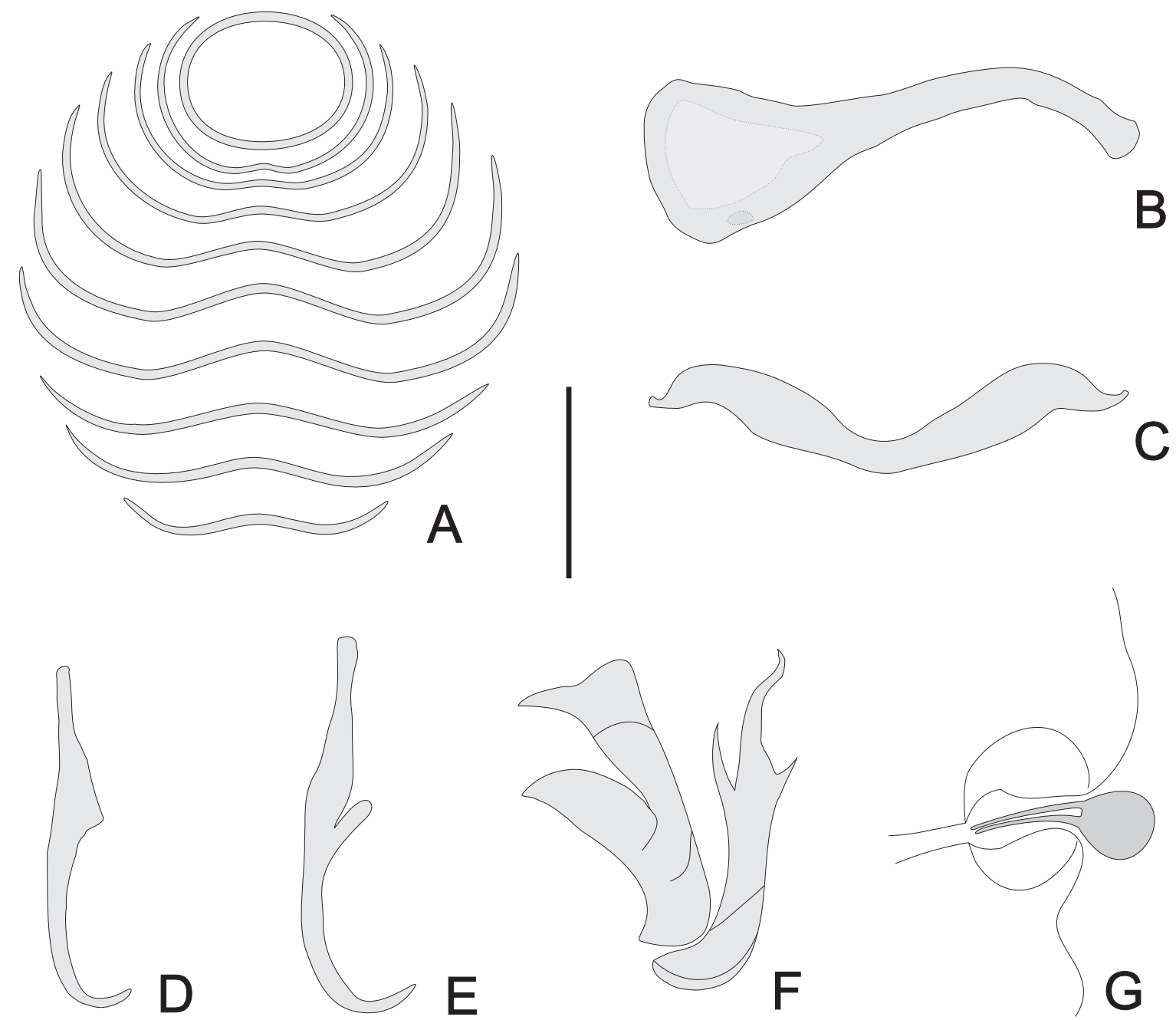

Fig. 5. Lamellodiscus triacies sp. n. from Dentex macrophthalmus off Dakar, Senegal. A - lamellodisc ("ignoratus" type); B - dorsal bars; $\mathbf{C}$ - ventral bar; D - dorsal anchor; $\mathbf{E}$ - ventral anchor; $\mathbf{F}$ - male copulatory organ; $\mathbf{G}$ - vaginal aperture and small body. Scale bar $=25 \mu \mathrm{m}$.

present. Two simple lateral intestinal caeca not united posteriorly. Subspherical testis, intercaecal in posterior half of body. Vas deferens emerging from antero-sinistral side of testis, not encircling left intestinal caecum, enlarging to form seminal vesicle. Vas deferens passing on right side, anterior to $\mathrm{MCO}$. Prostatic reservoir pyriform, anterior to MCO. MCO of "lyre" morphology, with two sclerotised, articulated pieces. Simple piece J-shaped, s: 46 $(41-49, \mathrm{n}=27)$ long, with three sharp spines, median biggest. Bifurcated piece with lateral tapered branch $\mathrm{lb}$ : $20(18-22, \mathrm{n}=27)$ shorter than axial branch ab: $27(25-$ $30, \mathrm{n}=27$ ). Distal part of axial branch enlarged. Ovary median, subequatorial, anterior to testis, looping dorsoventrally around right intestinal caecum. Mehlis' glands and ootype not observed. Vaginal aperture sinistral with funnel-shaped opening, enlarged on vaginal chamber often filled with a very small bulb (spermatophore?), diameter $=10 \mu \mathrm{m}$ (Fig. $5 \mathrm{G})$; connection with seminal receptacle not seen. Vitelline follicles lateral, coextensive with intestinal caeca, contiguous anterior to prostatic reservoir and posterior to testis. Eggs not seen.

Type host: Dentex macrophthalmus (Bloch, 1791) (Sparidae, Perciformes).

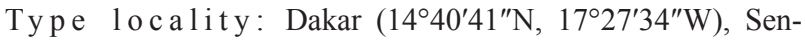
egal.

Other loc ality: Rabat ( $\left.34^{\circ} 1^{\prime} 47^{\prime \prime} \mathrm{N}, 6^{\circ} 49^{\prime} 49^{\prime \prime} \mathrm{W}\right)$, Morocco.

$\mathrm{S}$ ite of infection: Gills between secondary gill lamellae.

Type materia 1: Holotype (mounted in ammonium picrateglycerol): MNHN No. HEL 165 Tf 190; 9 paratypes (mounted in ammonium picrate-glycerol): MNHN Nos. HEL $165 \mathrm{Tf}$ 190, HEL 166 Tf 191, HEL 167 Tf 192; 6 paratypes (mounted in ammonium picrate-glycerol): BMNH 2010.8.11.11-16 and 2 paratypes (mounted in ammonium picrate-glycerol): IPCAS No. M-510.

Prevalence: $56 \% ; 88$ infected of 157 fish examined.

Etymology: From the Latin "tria", meaning three, and "acies", meaning point, to describe the form of simple piece of MCO. 
Remarks. From the morphology of the squamodisc, dorsal lateral bars and MCO, this new species belongs to the "ignoratus" group (Oliver 1987) and "ignoratus" s. st. subgroup (Amine and Euzet 2005). Lamellodiscus triacies can be easily distinguished from all species of this subgroup by the morphology of the simple piece of $\mathrm{MCO}$ with three sharp spines.

\section{DISCUSSION}

The three new Lamellodiscus species described here from Dentex macrophthalmus all belong to the "ignoratus" group (according to the shape of the lamellodisc and the "lyre"-shaped MCO). Until now, this group has also been characterised by the presence, at the level of the vaginal chamber, of a globular mass, whose nature and role were discussed by Neifar et al. (2004). This mass is also present in L. toguebayei and. L. vicinus, but not in L. triacies, in which the vaginal aperture in adult specimens seems to be closed by a small body resembling a small pseudo-spermatophore as recorded in Diplectanum aequans (Wagener, 1857) (see Oliver 1987, Silan et al. 1983).

As concluded by Oliver (1987), the variability of sclerotised structures of Lamellodiscus species may represent generic features. Monophyly of Lamellodiscus is questioned by Kritsky et al. (2000) and Desdevises (2001). Cladistic data of Domingues and Boeger (2008) failed to identify synapomorphy of Lamellodiscus species and these authors retain all species in the genus.

The currently known 55 species of Lamellodiscus have a close morphological and anatomical resemblance. However, sclerotised structures allow the distinction of morphological groups based on the morphology of squamodisc and of morphological types based on the morphology of MCO. But morphological groups and morphological types are generally not concordant (except for "ignoratus" group and "lyre" type) and do not permit to propose new taxonomic categories. Extensive cladistic analysis must be performed.

Acknowledgements. The authors are grateful to the French embassy in Dakar for U3E project grants and Khaled Bin Sultan Living Oceans Foundation for financial support (A. Diamanka) as well as to the French embassy in Tunis for SSHN grants (L. Neifar). We are also grateful to Dr. G. Rodjuk from the University of Kaliningrad for searching for the type material of $L$. dentexi. We want also to thank the two anonymous referees and the Editor for valuable comments on the manuscript.

\section{REFERENCES}

Aljoshrina L.D. 1984: New species of the family Diplectanidae (Monogenea) in the South-East Atlantic. Zool. Zh. 63: 12531256. (In Russian.)

Amine F., Euzet L. 2005: Deux espèces nouvelles du genre Lamellodiscus Johnston \& Tiegs, 1922 (Monogenea: Diplectanidae) parasites de Sparidae (Teleostei) des côtes de l'Algérie. Syst. Parasitol. 60: 187-196.

Amine F., Euzet L., Kechemir-Issad N. 2006: Description de deux nouvelles espèces de Lamellodiscus Johnston \& Tiegs, 1922 (Monogenea: Diplectanidae) du groupe morphologique 'ignoratus', parasites de Diplodus sargus et D. vulgaris (Teleostei: Sparidae). Syst. Parasitol. 64: 37-45.

Amine F., Euzet L., Kechemir-Issad N. 2007: Description de Lamellodiscus confusus n. sp. (Monogenea: Diplectanidae) parasite de Sarpa salpa (Teleostei: Sparidae). Parasite 14: 281285.

BAtes J.W. 1997: The slide-sealing compound "Glyceel”. J. Nematol. 29: 565-566.

Bellemans M., Sagna A., Fischer W., Scialabba N. 1988: Fiches FAO d'Identification des Espèces pour les Besoins de la Pêche. Guide des Ressources Halieutiques du Sénégal et la Gambie (Espèces Marines et d'Eaux Saumâtres). FAO, Rome, 255 pp.

Blache J., Cadenat J., Stauch A. 1970: Clés de Détermination des Poissons de Mer Signalés dans l'Atlantique Oriental entre le $20^{\mathrm{e}}$ Parallèle N. et le $15^{\mathrm{e}}$ Parallèle S. Faune Tropicale 18 . ORSTOM, Paris, 479 pp.

Boudaya L., Neifar L., Euzet L. 2009: Diplectanid parasites of Lithognathus mormyrus (L.) (Teleostei: Sparidae) from the Mediterranean Sea, with the description of Lamellodiscus flagellatus n. sp. (Monogenea: Diplectanidae). Syst. Parasitol. 74: 149-159.
Desdevises Y. 2001: Recherche des déterminants de la spécificité parasitaire dans le modèle Lamellodiscus (Diplectanidae, Monogenea) - Sparidae (Teleostei) en Méditerranée. Thèse, Université de Montréal et Université de Perpignan, 315 pp.

Domingues M.V., Boeger W.A. 2008: Phylogeny and revision of the Diplectanidae Monticelli, 1903 (Platyhelminthes: Monogenoidea). Zootaxa 1698: 1-40.

Euzet L., Oliver G. 1967: Diplectanidae (Monogenea) de Téléostéens de la Méditerrannée occidentale. IV. Quelques Lamellodiscus Johnston et Tiegs, 1922 parasites de poissons du genre Pagellus Cuvier, 1829 (Sparidae). Ann. Parasitol. Hum. Comp. 42: 407-425.

Justine J.-L. 1985: Étude ultrastructurale comparée de la spermiogenèse des Digènes et des Monogènes (Plathelminthes). Relations entre la morphologie du spermatozoïde, la biologie de la fécondation et la phylogénie. Thèse d'État, Université des Sciences et Techniques du Languedoc, Montpellier II, France, 230 pp.

Justine J.-L. 2007: Parasite biodiversity in a coral reef fish: twelve species of monogeneans on the gills of the grouper Epinephelus maculatus (Perciformes: Serranidae) off New Caledonia, with a description of eight new species of Pseudorhabdosynochus (Monogenea: Diplectanidae). Syst. Parasitol. 66: 81-129.

Justine J.-L., Briand M.J. 2010: Three new species, Lamellodiscus tubulicornis n. sp., L. magnicornis n. sp. and L. parvicornis n. sp. (Monogenea: Diplectanidae) from Gymnocranius spp. (Lethrinidae: Monotaxinae) off New Caledonia, with the proposal of the new morphological group 'tubulicornis' within Lamellodiscus Johnston \& Tiegs, 1922. Syst. Parasitol. 75: 159-179.

Kritsky D.C., Jiménez-Ruiz F.A., Sey O. 2000: Diplectanids (Monogenoidea: Dactylogyridea) from the gills of marine fishes of the Persian Gulf off Kuwait. Comp. Parasitol. 67: 145-164. 
Malmberg G. 1957: On the occurrence of Gyrodactylus on Swedish fishes. Skrifterutgivna av Sodra Sveriges Fiskeriforening, 1956: 19-76. (In Swedish, with a Summary in English.)

NeIfar L. 2008: Lamellodiscus crampus sp. nov. (Monogenea, Diplectanidae), a parasite of Dentex maroccanus (Teleostei, Sparidae) from off Tunisia. Acta Parasitol. 53: 258-262.

Neifar L., Euzet L., Oliver G. 2004: Lamellodiscus (Plathelminthes, Monogenea, Diplectanidae) nouveaux parasites branchiaux des poissons marins du genre Pagrus (Teleostei, Sparidae). Zoosystema 26: 365-376.

Nelson J.S. 2006: Fishes of the World. $4^{\text {th }}$ ed. John Wiley \& Sons, Inc., Hoboken, New Jersey, 624 pp.

Oliver G. 1987: Les Diplectanidae Bychowsky, 1957 (Monogenea, Monopisthocotylea, Dactylogyridae). Systématique. Biologie. Ontogénie. Écologie. Essai de phylogenèse. Thèse d'État,

Received 18 June 2010
Académie de Montpellier, Université des Sciences et Technique du Languedoc, Montpellier, $434 \mathrm{pp}$.

Oliver G. 1992: La spécificité parasitaire des Diplectanidae Bychowsky, 1957 (Monogenea, Monopisthocotylea): un facteur pour la connaissance des poissons-hôtes. Cybium 16: 361-366.

Poulin R., Mouillot D. 2005: Host specificity and the probability of discovering species of helminth parasites. Parasitology 130: 709-715.

Quéro J.C., Hureau J.C., Karrer C., Post A., Saldanha L. 1990: Check-list of the Fishes of the Eastern Tropical Atlantic (CLOFETA). JNICT/SEI/UNESCO, Paris, $1492 \mathrm{pp.}$

Silan P., Euzet L., Maillard C. 1983: La reproduction chez Diplectanum aequans (Monogenea, Monopisthocotylea). Nouvelles données sur l'anatomie du complexe génital et son fonctionnement. Bull. Soc. Fr. Parasitol. 1: 31-36. 